\title{
Ironia dos gêneros em Lucinde de Friedrich Schlegel
}

\author{
Giorgia Cecchinato - UFMG
}

O romance Lucinde, publicado em quatro partes a partir do 1799, se por um lado provocou escândalo e indignação no público $^{1}$, também foi, por outro lado, recebido com grande entusiasmo $^{2}$. Tal reação se explica tanto pela forma experimental de Lucinde como por seu conteúdo, julgado escandaloso por alguns contemporâneos. Formalmente, a obra apresenta-se como exemplo do que Schlegel chama de "poesia universal progressiva" (Schlegel,1997, p. 64, fragm.116), ou seja, uma narração aberta, que torna possível a fusão e a convivência de diferentes estilos

\footnotetext{
${ }^{1}$ Lembramos apenas dois escritos "anti-Lucinde" , o do escritor F. Nicolai, "Vertrauten Briefen von Adelheid B** an Ihre Freundin Julie S." de 1799 e o, publicado anônimo em 1800 com o título "Drey Briefe an ein humanes Berliner Freudenmädchen über die Lucinde von Friedrich Schlegel", ver Schmitz, 1992, pp. 257-258. O autor documenta a reação polêmica contra o movimento romântico em geral. O romance Lucinde representou uma alvo privilegiado de crítica por parte dos anti-romanticos.

2 O mais famoso escrito em defesa de Lucinde, além de um dos poucos, foi o do amigo F. Schleiermacher: "Briefen über Friedrich Schlegel's Lucinde zur richtigen Würdigung derselben", ver Ibid.,p. 258.
} 
e de diversos gêneros literários (estilo epistolar, idílio, drama e comedia). À primeira vista, a obra de Schlegel pode parecer caótica. Schiller, por exemplo, numa carta a Goethe, criticou-a duramente, acusando-a de ser uma mistura sem equilíbrio nem forma ${ }^{3}$. Mas, para Schlegel, a nova poesia que propunha deveria ser a expressão máxima da liberdade do artista tanto para representar seus sentimentos quanto para vivificar sua reflexão. Nessa proposta, a reflexão, ou seja, o pensamento filosófico, precisa da poesia e do caos, de outro modo ficaria amarrada apenas a conceitos abstratos e enclausurada em sistemas dogmáticos, distantes da vida e da realização efetiva da liberdade.

Já o conteúdo de Lucinde, julgado escandaloso e pornográfico pelos contemporâneos, conta a história do amor livre de Julius e Lucinde, narrada principalmente por Julius. O tema erótico do romance pode ser lido como uma crítica a modelos tradicionais de família, apresentando protagonistas que se dão conta de que o amor é condição necessária e suficiente para ligar duas pessoas, dispensando, por isso, todo contrato institucional. Como consequência natural, acabando-se o amor, também deve se terminar o casamento. A liberdade de desfazer uma ligação sem mais nada de vivo, que hoje em dia pode parecer obviedade, representava ousadia rara nos séculos XVIII e XIX, por mais que o divórcio fosse legalizado. Ousadia tanto maior, porque Schlegel a representava como condição para realização perfeita da humanidade. É possível ter uma noção muito mais clara da ousadia de Schlegel se confrontarmos Lucinde com a Doutrina do direito de Kant, de 1797. Concebido nessa obra em termos jurídicos, o casamento não passaria de um mero contrato para

\footnotetext{
3'Ver a Carta n.625 de Schiller a Goethe de 17 de Julho de 1799.
} 
regular o uso recíproco dos órgãos sexuais dos casados ${ }^{4}$.

Lucinde, contudo, não é um caso isolado, por mais escandaloso que pôde parecer. De fato, na mesma época, a instituição do casamento era colocada em cheque em várias formas e de diferentes lados. Basta pensar, aqui, no romance de Goethe As afinidades eletivas de 1809. A vida dos dois protagonistas, Charlotte e seu marido Eduard, é destruída pela atração irresistível, quase química, que sentem respetivamente pelo Capitão e por Ottilie. Apesar da complexidade dos elementos, muito bem ressaltada por W. Benjamin, o que está em jogo, nas Afinidades Eletivas, vai muito além do questionamento acerca da legitimidade da separação conjugal. Também estão em jogo, na obra de Goethe, a questão da essência da paixão erótica e do caráter próprio do compromisso matrimonial. Não é de estranhar, assim, que também essa obra de Goethe tenha sido alvo de duras críticas por parte dos leitores mais tradicionalistas ${ }^{5}$.

Há um traço, porém, que é peculiar à obra de Schlegel. Tratase de sua tentativa de superar o dualismo entre amor sensual e amor espiritual não apenas pela perspectiva platônica de elevação do eros carnal ao eros espiritual, mas pela relação, necessária, de complementariedade e de ação reciproca entre as duas formas. Para que estas possam atuar reciprocamente, é preciso que os próprios amantes sejam capazes de reconhecimento recíproco, o que implica, por sua vez, que não haja entre eles nem relação de dominação nem disparidade essencial. Schlegel propõe, com Lucinde, uma imagem da mulher, ou melhor, de caráter feminino, muito avançada, rica de aspectos interessantes. Schlegel crítica a idealização da mulher, que acaba por fixar ape-

\footnotetext{
${ }^{4}$ Ver Kant, 2003, p. 121.

${ }^{5}$ Cf. Benjamin, 2009, pp. 18-21.
} 
nas um ou alguns dos componentes do carácter feminino. Mãe, amiga, amante, interlocutora de diálogos filosóficos e musa inspiradora, Lucinde incarna todos estes lados ao mesmo tempo, que devem ser reconhecidos em todas as mulheres e em cada uma delas.

A questão da emancipação feminina e da importância e atualidade do ideal encarnado por Lucinde, assim como o contexto biográfico e histórico em que se desenvolvem, já foram objeto de estudos literários e das ciências sociais ${ }^{6}$. Falta ainda, porém, um estudo filosófico sobre o texto. Somente se considerar o contexto filosófico especifico em que a obra amadurece é possível entender o significado e o alcance que esta obra peculiar teve e ainda pode ter, talvez de maneira diversa, para os leitores de hoje. Isso significa que é preciso levar em conta o complexo debate pós-kantiano sobre a possibilidade de conjugar natureza e liberdade, sentimento e razão, bem como a exigência de fundamentação de uma nova forma de filosofia, quer dizer, um novo modelo de racionalidade, proposto primeiro por J.G. Fichte e, em medida menor, por outros membros do círculo romântico de Jena, como Novalis e Schelling. De outro modo, dificilmente será possível compreender o significado que esta obra peculiar teve e ainda pode ter hoje. Se a execução dessa tarefa é por ora muito ampla, alguns pontos importantes podem, contudo, ser apresentados desde já.

\section{O dualismo masculino-feminino}

A reflexão sobre o papel da mulher na sociedade faz parte do impulso renovador da Revolução Francesa e da Aufklärung.

${ }^{6}$ Veja por exemplo Rehme-Iffert, 2012. 
A afirmação da igualdade dos homens, o imperativo de difundir amplamente a cultura e a proposta de elaborar um novo ideal de humanidade -tudo isso trouxe consigo a tarefa urgente de pensar a questão do papel das mulheres neste processo como um todo. A primeira edição da Encyclopaedia Britannica de 1771 explica o verbete "Mulher", a definição antropológica: "fêmea do homem"; do ponto de vista da história natural, define a mulher como "complemento do homem", sem lhe reconhecer, portanto, autonomia alguma. Na explicação comparativa com respeito ao homem, segundo as diferenças naturais, ela é definida negativamente a partir do caractere masculino. Em quanto o homem é forte, ativo, dotado de razão, a mulher é fraca, passiva, embora naturalmente dotada de graça e beleza. Para maiores explicações sobre o que é uma mulher, a Encyclopaedia remete ao verbete "Casamento".

Já Rousseau no Emílio ou da educação, dedicado à questão da educação, afirma que homens e mulheres são iguais por necessidades e capacidades. Contudo, ainda assim, é apenas no capítulo V que aparece a questão especifica da educação feminina, quando está em jogo a companheira ideal que deve ser encontrada para o Emilio. Nesse ponto, é bem limitado o papel que Rousseau confere à educação das mulheres, restringindo-o à determinação e ao desejo primário das mulheres: nada mais do que agradar aos homens em vista do casamento e da possibilite de tornar-se esposa e mãe ${ }^{7}$.

A necessidade de uma instrução para as mulheres que não se limite à vida social e ao papel de esposa, mas também contemple o reconhecimento da igualdade de direitos para homens e mulheres torna-se também um assunto importante nesta época.

${ }^{7}$ Cf. Rousseau, 1994, pp. 423-581. 
No cenário alemão, lembramos, em primeiro lugar, von Hippel que em 1792 publica o tratado textitÜber die bürgerliche Verbesserung der Weiber.

Também Friedrich Schlegel se ocupa da questão da educação das mulheres nos escritos Sobre Diotima e Sobre o caractere feminino dos poetas gregos, ambos de 1797. Mostra, então, como Safo e Diotima, que, no Banquete de Platão, se incumbe de introduzir Socrates na filosofia, são exemplos brilhantes de como as mulheres não apenas podem, mas também devem dedicar-se à filosofia e à arte bela. Não faz sentido, segundo F. Schlegel, excluir as mulheres da vida intelectual e do debate filosófico ${ }^{8}$.

Se é verdade que estes primeiros escritos são frutos de anos de estudo da história, da filosofia e da poesia grega, também é verdade que foram inspirados pelo encontro com Caroline Schlegel, a esposa do irmão August e depois esposa do filósofo F. Schelling. Mulher extraordinária, sem dúvida, pois foi tão nãoconformista e atrevida que acabou por receber o apelido de "Dona Diabo" (Frau Teufel). Foi Caroline, pois, que despertou em Friedrich o interesse pela questão da formação intelectual das mulheres. Outro elemento biográfico fundamental no desenvolvimento da atividade intelectual de F. Schlegel é o amor pela filha de M. Mendelsshon, esposa de um rico banqueiro, Dorothea Veit. Logo que Friedrich e Dorothea se conheceram no salão de Henriette Hertz, explodiu uma paixão irrefreável. Os dois resolveram desafiar a sociedade conservadora, indo morar juntos antes mesmo que fosse formalizado o pedido de separação oficial. O amor por Dorothea foi, sem dúvida, inspirador para F. Schlegel. Apenas dois anos depois do primeiro encontro, em 1799, publicou o romance Lucinde. O paralelo entre a paixão

\footnotetext{
${ }^{8}$ Schlegel F., $1979^{\mathrm{a}}$.
} 
explosiva e a paixão de Julius e Lucinde, é, sem dúvida, um dos ingredientes que mais provocou escândalos, tendo chegado a suscitar a perplexidade e até mesmo o constrangimento da própria Dorothea e de Novalis, entre outros, como dão testemunho as cartas entre Dorothea e Caroline e Novalis.

Porém, a teoria do amor exposta na Lucinde vai muito além da revisitação poética de um fato biográfico, mas está profundamente enraizada no debate filosófico pós-kantiano. Não se trata aqui apenas de fundamentar ou defender a igualdade entre homens e mulheres, nem de defender os direitos do amor carnal juntamente com a profundeza do amor espiritual. Tratase também de dar uma forma poética a uma teoria filosófica que permite pensar a identidade nas diferenças, bem como o reconhecimento e a união das diferenças.

No contexto da época, torna-se urgente a tarefa de defender a relacao de complementariedade entre homens e mulheres, preservando, contudo, as características diferentes de ambos ${ }^{9}$. A partir da apropriação que os alemães, Kant em particular, fazem do Iluminismo e dos ditos empiristas ingleses, a questão da diferença e da complementariedade dos gêneros se torna parte de uma reflexão estética em sentido mais geral. Foi Burke, em sua Investigação filosófica sobre a origem de nossos sentimentos do belo e do sublime (1757), que retomou em termos estéticos a diferenciação, de matriz aristotélica, do homem como princípio ativo e da mulher como passivo, continuamente reelaborada na tradição religiosa e filosófica. Para o filosofo inglês, a mulher e

9 Esta necessidade coloca-se principalmente no contexto alemão. Na Inglaterra e na França a situação social era diferente. Destaca-se, por exemplo, a importância que as prerrogativas femininas adquiriram na França do século XVIII por causa principalmente do papel social das mulheres, ver Figueiredo 2015. Sobre isso ver também Badinter, 1984. 
o homem representam exemplos de duas naturezas opostas que originam os dois sentimentos opostos do belo e do sublime. A primeira é bela em sentido próprio, caraterizada pela sensibilidade e pela leveza, associada aos aspectos mais tranquilizantes e protetivos da natureza. Já o homem é sublime, racional, sério, tendo um caráter mais próximo do aspecto violento e ameaçador da natureza. Kant retoma os mesmos argumentos em seu pequeno tratado pré-crítico Observações sobre o sentimento do belo e do sublime de 1762. Na terceira secção, intitulada $D a$ diferença entre o sublime e o belo na relação entre o sexo, Kant admite que

O belo sexo possui tanto entendimento quanto o sexo masculino; trata-se, porém, de um belo entendimento, enquanto o nosso deve ser um entendimento profundo [...]. Meditação profunda e uma longa contemplação são nobres, porém difíceis, e não convêm a uma pessoa na qual os estímulos espontâneos não devem mostrar outra coisa que uma bela natureza. O estudo laborioso ou a especulação penosa, mesmo que uma mulher nisso se destaque, sufocam os traços que são próprios a seu sexo; e, não obstante dela façam, por sua singularidade, objeto de uma fria admiração, ao mesmo tempo enfraquecem os estímulos por meio dos quais exerce seu grande poder sobre o outro sexo. A uma mulher que tenha a cabeça entulhada de grego, como a senhora Dacier, ou que trave disputas profundas sobre mecânica, como a marquesa de Châtelet, pode mesmo faltar uma barba, pois com esta talvez consigam expri- 
mir melhor o ar de profundidade a que aspiram [...] (Kant, 1993, p. 49).

Kant propõe mais uma vez a distinção entre belo e sublime na Critica da faculdade de juizo de 1790. Nesta obra a perspectiva que Kant adota é puramente transcendental, eliminando, assim, todas as referências antropológicas. Enquanto desparecem os temas do feminino e do masculino, reforçam-se a interligação do belo com o sentimento, ainda que puro, e a implicação do sublime com razão, ainda que por meio de um sentimento. Com essa obra, como é sabido, Kant procura superar o dualismo que a filosofia transcendental estabelecera, com as duas primeiras Críticas, entre natureza e liberdade, mundo sensível e mundo suprassensível. A solução apontada por Kant, em particular, a natureza apenas subjetiva, ainda que universal, da faculdade de julgar não satisfaz os críticos da filosofia kantiana nem seus adeptos nem, em geral, os que, com base na "revolução copernicana", almejam a fundamentação de uma filosofia nova. Entre estes cabe lembrar a proposta de F. Schiller e de J.G. Fichte. O primeiro, nos escritos filosóficos, manteve substancialmente o dualismo kantiano razão-sensibilidade, indicando como única possibilidade de superação consequente o desenvolvimento harmônico da humanidade pela educação estética, recurso que, segundo o artista-filosofo, permitiria a otimização e interação dos dois. Esta interação, porém, é aparência (Erscheinung), não sendo, portanto, algo real, mas a capacidade de suspender todas as realidades. A aparência, tal como ocorre na reflexão estética kantiana, permitiria a suspenção de toda e qualquer finalidade externa e de todo interesse. Por isso, podemos afirmar que a solução de Schiller não se afasta muito do caráter subje- 
tivo do juízo estético e, tal como ocorre com a estética kantiana, não supera o abismo entre sensibilidade e razão. Em última análise, mostra apenas que, entre estes dois domínios reais, só pode haver uma ponte, ou melhor, uma aparência de ponte. É significativo que, nos escritos que preparam a teoria da educação estética exposta nas Cartas sobre a educação estética do homem (1796) e na obra Graça e Dignidade (1795), por exemplo, Schiller também faça a distinção entre graça e dignidade com base na distinção entre o caráter gracioso, feminino, e o caráter digno e nobre, ou seja, masculino ${ }^{10}$.

O mesmo caráter binário, em relação à distinção entre razão e sensibilidade, passividade e atividade, homem e mulher, volta na poesia $A$ dignidade das mulheres. De modo lírico, Schiller repropõe, nessa obra, a imagem da mulher tranquilizante e protetora, que se encontra em casa entrelaçada de rosas enquanto o homem leva uma vida frenética e, passando de uma luta a outra, só encontra abrigo e descanso no lar.

Honrai as mulheres! Elas entrançam e tecem

Rosas sublimes na vida terrena,

Entrançam do amor o venturoso laço

E, através do véu casto das Graças,

Alimentam, vigilantes, o fogo eterno

De sentimentos mais belos, com mão sagrada.

[...]

Nos reinos do poder masculino,

Vence, por direito, a força,

10 Schiller, 2008, pp. 35 ss. 
Pela espada se impõe o cita

E escravo se torna o persa, Esgrimem-se entre si, em fúria, Ambições selvagens, rudes, E a voz rouca de Éris domina, Quando a Cárite se põe em fuga.

Porém, com modos brandos e persuasivos, As mulheres conduzem o ceptro dos costumes, Acalmam a discórdia que, raivosa, se inflama, $\grave{A}$ forças hostis que se odeiam Ensinam a maneira de ser harmoniosa, E reúnem o que no eterno se derrama ${ }^{11}$.

É significativo que Caroline Schlegel, ao escrever para a filha comentando a leitura da poesia de Schiller, afirme literalmente que ela e o marido "caíram da cadeira de tanto rir" . Também A. Schlegel escreveu uma parodia muito bem humorada da divisão de papéis, que nos círculos intelectuais já era considerada muito antiquada.

Honrai as mulheres! tricotam zelosas

Para o homem meias quentes e sedosas

Cosem-lhe as calças todas rasgadas

Preparam-lhe sempre a refeição

11 Trad. M. Do Sameiro Barroso. 
Limpam as bonecas soltas no chão

Sobrevivem com misera mesada

Rosna como urso na jaula

Nos filhos sem parar dá bronca

E à noite com a esposa na cama

Vira de lado e já ronca ${ }^{12}$.

\section{Superação do dualismo}

Tentativa de superar, de modo mais profundo e fundamentado, os dualismos típicos da filosofia de Kant foi feita por J.G. Fichte. A radicalidade de seu projeto filosófico se encontra já na alteração que promove do método filosófico. A filosofia, devendo deixar de ser simples tendência ao saber, conforme indicado em seu nome, tem de transformar-se no próprio conhecimento do conhecimento: "doutrina da ciência". Em grandes linhas, projeto fichteano pretende, tomando como ponto de partida o "espírito" da filosofia kantiana, considerada inacabada em sua letra, realizar a fundamentação do saber e da consciência que forma este saber. Constitui momento fundamental da realização deste

${ }^{12}$ Citado em Reheme-Iffert, 2012, p. 113. Eis o texto alemão: "Ehret die Frauen! Sie stricken die Strümpfe/Wohlig und warm, zu durchwaten die Sümpfe/Flicken zerrissene Pantalons aus/Kochen dem Manne die kräftigen Suppen/Putzen den Kindern die niedlichen Puppen,/Halten mit mäßigem Wochengeld haus;/Doch der Mann, der tölpelhafte/Find't am Zarten nicht Geschmack/Zum gegornen Gerstensafte/Raucht er immerfort Tabak/Brummt wie Bären an der Kette/Knufft die Kinder spät und früh;/Und dem Weibchen, nachts im Bette,/Kehrt er gleich den Rücken zu". A citação foi traduzida por Paulo R. Licht dos Santos e G. Cecchinato. 
projeto a inclusão dos impulsos na natureza dialética da razão; desse modo se manteria a unidade do eu, superando, por fim, o "abismo" entre razão e sensibilidade.

Este quadro, ainda que breve, permite dar consistência a nossa proposta de de interpretação e leitura: somente se pode compreender o sentido e o alcance da reflexão de F. Schlegel sobre as questões de gênero na Lucinde a partir de sua reflexão e apropriação da filosofia de Fichte.

Isso significa que devemos levar em conta não apenas os escritos ditos "filosóficos" de Schlegel, mas também as obras poéticas, em plena conformidade como a concepção de F. Schlegel de que verdadeira filosofia precisa se expressar poeticamente e de maneira experimental. Esta perspectiva permite entrever desde já que o romance Lucinde não é apenas uma obra literária rica e estimulante, mas representa um tratado poético-filosófico sobre as relações humanas, as amorosas em particular. Está em jogo aqui a relação complexa e multifacetada com a alteridade, assim como o sentido do reconhecimento. Quando Julio dedica um ditirambo a Lucinde, afirma:

Entre todas as situações esta é a mais ironicamente inspirada e a mais bela: quando trocamos um com o outro os nossos papeis e competimos com alegria infantil para descobrir quem é o melhor na imitação do outro, se você consegue melhor imitar o ímpeto sem freio do homem ou se eu consigo com melhor resultado imitar o convidativo oferecer-se da mulher. Sabe que esta doce brincadeira oferece, a meu ver, atrativas que vão bem além das próprias? [...] Nisso já vejo uma brilhante e significativa alegoria do masculino e do fe- 
minino rumo á plena e total humanidade. (Schlegel, 2011, p. 19.)

Esta afirmação poderia, à primeira vista, não parecer diferente da perspectiva assumida por Schiller na poesia Wurde der Frauen ou da posição de vários outros intelectuais da época. Por exemplo, W. Von Humboldt também teoriza acerca da complementariedade, na diferença, de homens e mulheres. Contudo, somente quando consideramos o elemento da ironia e seu sentido em F. Schlegel é que somos capazes de compreender seu projeto originário de reformulação da filosofia de Fichte. Quer dizer, somente dessa perspectiva podemos enxergar um sentido mais profundo desta afirmação e da proposta de F. Schlegel de permanecer fiel ao projeto originário de Fichte: compreender e realizar a liberdade do eu como autodeterminação.

Por isso também a proposta de Schlegel é inseparável de uma crítica radical do sistema de Fichte, a partir da qual ganha consistência sua teoria sobre a ironia. Contra a rigidez de uma forma de sistema que, pretendendo ser científica, não consegue deixar a abstração; contra a convicção de que a filosofia precisa apoiar-se num ponto de partida certo para poder avançar segundo um método dedutivo rigoroso, Schlegel desenvolve a teoria da ironia, modo de distanciar-se de todas as formas dogmáticas de pensamento por um pensar flexível, aberto e dinâ$\operatorname{mico}^{13}$.

13 Desconfiança em relação ao pensamento especulativo não significa se entregar ao relativismo e à subjetividade. Trata-se na verdade de um aprofundamento da análise dos limites do conhecimento de marca Kantiana. Ver Suzuki, 1998, cap. VI, pp. 139-166. Aqui o autor também destaca as ligações entre o conceito de ironia e o de gênio. A mesma perspectiva, que quer "salvar" F. Schlegel das acusações de subjetivismo e irracionalismo de 
A ironia torna-se, então, indispensável para entender, representar e também para ser um eu, isto é, um sujeito que age praticamente e espiritualmente, enfrentando de modo livre novas situações. Não se detém, por isso, num ponto de vista definitivo nem em uma identidade definitivamente estável, mas se mantém num processo contínuo de construção em relação a um não-eu: $u m t^{14}$.

Voltando à citação acima, podemos concluir que a troca de papel entre homem e mulher, assim como Julius fala, indica algo mais significativo para a humanidade. Indica que as características que parecem inatas, ligadas a uma espécie de estado de natureza, nada mais são que papeis, dos quais podemos tomar distância, tornando-nos conscientes de que são apenas papeis e, por isso, podemos trocá-los ou brincar com eles ou não. Contudo, é fundamental para o desenvolvimento da humanidade que a troca seja recíproca e flexível, ou, com outras palavras, irônica. Assim como deveria ser irônica a nossa atitude respeito a estas questões.

Nesse sentido, a proposta de Schlegel, com linguagem diferente e num contexto diverso, torna-se muito próxima da filosofa americana pós-estruturalista Judith Butler. A teoria da performatividade concebida por ela entende o gênero como fruto de atos reiterados. É a reiteração e a incapacidade de distanciamento para tomar consciência de alguns hábitos que nos fazem acreditar que alguns tipos de comportamentos ou atitudes sejam naturais. Na sua trajetória teórica, Butler desloca o eixo de seu interesse da questão da identidade feminina para o pro-

matriz hegeliana é adotada por Valpione e aplicada a esfera moral e politica, ver Valpione, 2015.

${ }^{14}$ Ver Frischmann, 2005, pp. 109-171. 
blema mais amplo do reconhecimento da alteridade em relação a todas as assim chamadas "minorias". Acompanha, assim, Foucault, no qual se inspira para sua teoria da performatividade, e retoma a filosofia de Hegel, em particular a figura da dialética entre senhor e escravo da Fenomenologia do Espírito. Apesar dessa proximidade, o estudo de Lucinde em seu próprio contexto filosófico e a investigação mais profunda sobre o parentesco da poesia universal de Schlegel com o projeto filosófico de Fichte permitem fornecer um modelo distinto de reconhecimento e de relação de identidade e de alteridade.

Se por ora deixamos em aberto esse campo de investigação, já é um ganho tê-lo esboçado nas linhas centrais. Sem considerar o contexto filosófico de Schlegel, sua crítica e apropriação da filosofia de Fichte, bem como a construção do conceito de ironia que surge daí, dificilmente se poderá compreender a atualidade e a originalidade de seu pensamento para a filosofia de gênero.

\section{Referências bibliográficas}

ARENDT, A. Rahel Vernhagen. Storia di una donna ebrea. Trad. it. Lea Ritter Santini. Milano: Il Saggiatore, 2004.

BADINTER, E. Emilia, Emilia. L'ambizione femminile in due ritratti di donna. Milano: Longanesi, 1984.

BENJAMIN, W. "As Afinidades eletivas de Goethe". In Ensaios reunidos sobre Goethe. Trad. M. Krausz Bornebusch, I. Aron, S. Camargo. São Paulo: Editora 34, 2009.

BUTLER, J. El género en disputa: el feminismo y la subversión de la identidad, Madrid, Sínteses, 1997.

FICHTE, J. G. A Doutrina da Ciência de 1794 e Outros Escritos. Trad. R. R. Torres Filho. Coleção os Pensadores. São 
Paulo: Nova cultural, 1988.

FRISCHMANN, B. Vom transzendentalen zum frühromantischen Idealismus. J. G. Fichte und Fr. Schlegel, Paderborn, Ferdinand Schöningh Verlag, 2006.

KANT, I. Observações sobre o sentimento do belo e do sublime. Tradução de Vinícius Figueiredo. São Paulo: Papirus Editora, 1993.

___. Metafisica dos costumes. Trad. Coletiva. Petrópolis: Vozes, 2010.

REHME-IFFERT, B. "Friedrich Schlegel über Emanzipation, Ehe und Liebe". Athenäum v. 12. 2002, pp. 111-132.

ROUSSEAU, J.J. Emílio ou da educação. 3. Edição. Trad. S. Milliet. Rio de Janeiro: 1995 Bertrand, 1995.

SCHLEGEL, F. "Über die Diotima". In: Behler, Ernst (Hrsg.): Kritische Friedrich-Schlegel-Ausgabe, Bd. 1: Studien des klassischen Altertums. München, Paderborn,Wien: Ferdinand Schöningh, 1979a. pp. 70 ss.

. O dialeto dos fragmentos. Trad. M. Suzuki. São Paulo: Iluminuras, 1997.

clam, 2011.

SCHILLER, F. Briefwechsel mit Goethe. In:http://gutenberg.spiegel.de/buch zwischen-schiller-und-goethe-zweiter-band-3683/3.

__- Sobre graça e dignidade. Trad. A. Resende. Porto Alegre: Movimento, 2008.

SCHMITZ, R. Die Ästhetische Prügeley. Streitschriften der antiromantischen Bewegung.

SUZUKI, M. O Gênio romântico. São Paulo: Iluminuras, 1998.

VALPIONE, G. "Poesie der Staatlichkeit in Fr. Schlegels Philosophie" in: Pauly/Ries, Staat, Nation und Europa in der 
politischen Romantik, Nomos, Baden-Baden, 2015. No prelo. 